\title{
The Medical Officer Experiences of Indonesia Women Futsal Team
}

\author{
Upik Rahmi*, Suci Tuti Putri \\ Nursing Adult \\ Universitas Pendidikan Indonesia \\ Bandung, Indonesia \\ *upikrahmi@upi.edu
}

\author{
Afianti Sulastri, Siti Zulfa \\ Farmasi \\ Universitas Pendidikan Indonesia \\ Bandung, Indonesia \\ afiantisulastri@upi.edu,zulfa@upi.edu
}

\begin{abstract}
Futsal is a kind of sport that has a high risk of being injured. Incident of injury can give serious consequence for player, team (especially when there is no substitute player who has the same quality), and public health system. The study shows that women tend to have ACL injury risk that is higher than men do $(2,4-9,5 \%)$. The study was aimed to describe experiences of medical officers to cope with women futsal athletes' injury. The study was set as descriptive qualitative study by using phenomenological approach that involved 3 members of medical officers by using purposive sampling technique. The data were collected through in depth interview and then were analysed thematically. The finding shows that medical officers of women futsal team have been able to cope with injury of the sport well. However, medical check-up, evaluation, and injury prevention process haven't been comprehensively conducted due to their background that doesn't come from medical profession.
\end{abstract} futsal

Keywords-experience; medical officers; sport injury; women

\section{INTRODUCTION}

Football can be considered as the most popular sport in the world and has been listed as the biggest sport association that consists of more than 200 million males and 21 million females as noted by FIFA [1]. FIFA has 203 members including national associations that represent more than 200 million of active plays whose 40 million members are women [2]. In addition to football, FIFA also regulates the world operation of futsal sport or indoor football. Futsal is firstly played in Uruguay. The popularity of this branch of football keeps increasing day by day in the world especially in Spain, Portugal, Russia, Holland, Belgium, and Italy, and also in Indonesia. The study shows that there are more than 12 million of futsal players that are listed as members in more than 100 countries. Futsal is played in a $38-42 \mathrm{~m} \times 18-25 \mathrm{~m}$ field, by using $3 \times 2 \mathrm{~m}$ ball (like handball), 2 × 20 minutes effective, where players can take turn to play and when time stops whenever the ball is outside the field. The game will last for 70 up to 80 minutes. Excellent technique of a futsal player is a consequence from the smaller size of ball that needs players to be able to manipulate the ball more correctly [3]. In addition, its smaller field $(20 \times 40 \mathrm{~m})$ also needs the players to experience constant pressure from their opponents. Thus, futsal players tend to be under pressure and to experience 1 on 1 pressure in almost all the game duration [4].
Futsal is a kind of sport that has a high contact and a high risk to be injured. A serious injury incident of a player can give serious consequence to the player, to the team (especially when there is no substitute player who has the same quality), and to public health system. The total cost for about 3864 knee injury is up to 4.268.014 \$, with the most incident experienced by women player. Another study also shows that women tend to have higher risk to ACL injury than men (2,4-9,5\% higher than men). Eren's study in 2016 that was conducted to 66 women athletes at the age $20,72 \pm 2,08$ ) shows that $57,00 \%$ from the total 93 injury incident happened in the lower extremity and 22 $(23.70 \%)$ happened to the upper extremity. The level of injury on ankle in general is $25(26,90 \%)$, knees $20(21,50 \%)$, rendah belakang $15(16,10 \%)$, hips/tighs /feet $11(11,80 \%)$, shoulder 8 $(8,60 \%)$, elbow $4(4,30 \%)$, hands / fingers $5(5,40 \%)$, and head /face $5(5,40 \%)$. Meanwhile, the proportion of bad injury/ traumatic injury is up to $73(78,50 \%)$, overtime play 20 $(21,50 \%)$, and the rest $24,70 \%$ of the total injury is caused by body contact with opponent players. Mufty et al states that injury on male futsal players frequently happened in the form of joints dislocation, while female futsal players tend to face muskulotendinous injury [5]. Proportionally, female tend to get worse injury than men ( $p<0,0001)$. Most of the injury happened to lower part of the leg $(73,4 \%)$, especially on knees $(30,4 \%)$ and ankle joints (17,9\%). Having the same sound, Juan et al (2016) found that proportion of injury happened more frequently during the match $(36,9 \%)$ compared to those during exercise $(11,4 \%$; $p<0,001)$. Non-contact injury is classified to be an injury that is considered worse than body contact injury $(51,0 \%$ vs $42,6 \%$; $p<0,001)$. Incident of injury occurrence on adult football players $(\geq 18$ y.o) was found higher compared to those who are younger than 18 y.o $(0,093$ vs 0,073 injury on every player every year, respectively; $p$ $<0,001)$.

Healing a disease or coping with injury is always important to be known and the technique and methods of curing diseases keeps developing [6]. Medical officers are kind of profession whose functions are to supply medical service, promote, maintain, and healing human health. Target of medical team is to ensure that athletes are in a good condition to play.

A competition will be tough for an athlete when their health condition is not good that makes them difficult to compete with others. The success of medical team and athletes' health 
condition tend to be incompatible. The success of medical team depends on team ability in maintaining the athletes' playing endurance in a match, which means that they are expected to make the longer endurance of the players.

\section{METHOD}

Medical officers consist of a doctor, nurse, and also coach that also plays role to be a medical officer. The medical officers consists of 5 members, however there are only 3 members who fit the requirements to be a medical officer. The study was set as descriptive qualitative study by using phenomenological approach. The data were collected through in depth interview that is recorder by tape recorder. The aims of the study are to explore experiences of medical officers in handling women futsal athletes' injuries. The participants of the study were selected purposively meaning that they are selected to fit the needs and focus of the study [7]. The participants of the study are members of medical officers of women futsal team who fit some criteria as follows: a) able to speak Indonesian fluently and to communicate clearly that will ease the researcher to grasp information given, b) become a member of medical futsal officers. The study was conducted in Bandung, Indonesia. The data gained from in depth interview were then reduced into a table to answer the research questions and were then analysed to make the data clear enough to be understood. The study was conducted to present a comprehensive picture about how women futsal athletes' injuries are handled. The data were collected by having in depth interview with participants of the study in futsal field. The interview was conducted by using Sundanese in 30-60 minutes for each participant. Participants' responses were recorded and also noted by the interviewer. After conducting interview, the data were then analysed and coded to answer the research questions correctly.

\section{RESULT}

TABLE I. PARTICIPANTS CHARACTERS BASED ON AgE, GENDER, EDUCATIONAL BACKGROUND, AND COACHING OF MEDICAL OFFICERS IN WOMEN FUTSAL ATHLETES UPI $(\mathrm{N}=3)$

\begin{tabular}{|l|l|l|}
\hline \multicolumn{1}{|c|}{ Characteristic } & Frequency (f) & \multicolumn{1}{c|}{ Percentage (\%) } \\
\hline Age & & \\
\hline $17-25$ y.o. & 0 & 0 \\
\hline $26-35$ y.o. & 2 & 66,7 \\
\hline $36-45$ y.o. & 0 & 0 \\
\hline $46-55$ y.o. & 1 & 33,3 \\
\hline Gender & & \\
\hline Male & 3 & 100 \\
\hline Female & 0 & 0 \\
\hline Educational background & & \\
\hline D3 & 0 & 0 \\
\hline S1 & 2 & 66,7 \\
\hline S2 & 0 & 0 \\
\hline S3 & 1 & 33,3 \\
\hline Coaching & & \\
\hline BTCLS & 0 & 0 \\
\hline ATCLS & 0 & 0 \\
\hline Handling sports injuries & 0 & 0 \\
\hline Others & 3 & 100 \\
\hline
\end{tabular}

Three male participants were involved in the study, two of them are around 26-35 y.o. and another one is around 46-55 y.o. They also come from different educational background, two of them are bachelor degree and one from doctoral degree. Participants have already had knowledge and skill about handling and curing injuries on sport through a formal education. The data gained from in depth interview and observation field note were then analysed by using content analysis technique. The data were classified based on theme as described in the following table:

TABLE II. CONTEXTUAL INFLUENCE IN RELATION TO EXPERIENCE OF MEDICAL OFFICERS IN HANDLING INJURIES OF WOMEN FUTSAL ATHLETES UPI

\begin{tabular}{|c|c|c|}
\hline Category & Sub theme & Theme \\
\hline $\begin{array}{l}\text { Role of medical officers in pre- } \\
\text { compettion phase }\end{array}$ & $\begin{array}{l}\text { Cheking athletes' } \\
\text { physical condition }\end{array}$ & $\begin{array}{l}\text { Cheking up } \\
\text { athletes' } \\
\text { health before } \\
\text { competiton }\end{array}$ \\
\hline $\begin{array}{l}\text { Initial assessment of sport } \\
\text { injuries }\end{array}$ & $\begin{array}{l}\text { Assessing } \\
\text { movement } \\
\text { Injuries } \\
\text { mechanism } \\
\text { Injuries location } \\
\text { Injuries history } \\
\text { Knowing the } \\
\text { tenderness }\end{array}$ & $\begin{array}{l}\text { Initial } \\
\text { Assessment of } \\
\text { sport injuries } \\
\text { through } \\
\text { active and } \\
\text { passive } \\
\text { movement }\end{array}$ \\
\hline Prevention of sport injuries & $\begin{array}{l}\text { Skills training } \\
\text { Regular exercise } \\
\text { Diet } \\
\text { Fast Handling of } \\
\text { injuries } \\
\text { Environmental } \\
\text { setting }\end{array}$ & $\begin{array}{l}\text { Preventing } \\
\text { injuries by } \\
\text { environmental } \\
\text { setting }\end{array}$ \\
\hline \multirow[t]{2}{*}{$\begin{array}{l}\text { Handling and healing sport } \\
\text { injuries }\end{array}$} & $\begin{array}{l}\text { Applying method } \\
\text { of Rest, Ice, } \\
\text { Compress, } \\
\text { Elevation }\end{array}$ & $\begin{array}{l}\text { Handling close } \\
\text { wounded } \\
\text { injuries } \\
\text { Handling open } \\
\text { wounded } \\
\text { injuries }\end{array}$ \\
\hline & $\begin{array}{l}\text { Controlling the } \\
\text { bleeding } \\
\text { Cleaning the } \\
\text { wounds } \\
\text { Giving medicine } \\
\text { Closing the } \\
\text { wounds }\end{array}$ & $\begin{array}{l}\text { Penanganan } \\
\text { luka terbuka } \\
\text { cedera } \\
\text { olahraga }\end{array}$ \\
\hline
\end{tabular}

The experience of medical officers in handling injuries of women futsal athletes from pre-competition phase, symptoms of sport injuries, prevention of sport injuries and handling and healing process of the injuries are interrelated one to another.

\section{A. Role of Medical Officers in Pre-competition Phase}

Experience of medical officers in handling athletes' injuries in pre-competition phase is usually dealing with checking athletes' health condition.

Based on the data collected, medical team admitted that a thorough and comprehensive medical check up to the athletes hasn't been done. In this phase, the medical officers only conducted anamneses to the injuries of the athletes. Besides, some treatments are also given before the match to prevent injuries among the athletes, such as conducting regular exercise and managing athletes' diet. To this case, participants give relatively the same response. 
“Actually, we haven't conducted a particular medical check up to the athletes" (P1)

"But.. to be honest, a health condition check up hasn't been done yet before having competition here. A comprehensive medical check up, such as checking athletes' cardiovascular condition hasn't been done yet." (P2)

"That's the case! I realize that a health condition is better to be conducted before a match, but until now, futsal team don't allow the athletes to have a health check up."(P3)

However, all participants responded that a particular treatment was given to the athletes before joining a match to avoid the athletes of being injured. The treatments cover asking the athletes' health condition, conducting regular exercise, and managing athletes' diet, as admitted by the participant below:

"So, we just asked the athletes if there is athlete who is not feeling well." (P1)

"because the medical officers here are coaches, therefore, as a coach, we can only give do preventive actions to protect athletes from injury in this case, by regular exercise and managing diet" (P2)

"So we just do physical test, it will let us know whether the athletes healthy and ready, although a team should actually have a health laboratory" (P2)

"Naturally, a coach has prepared athletes to join a competition. In this case, a coach also plays role as medical officers that can help athletes to avoid injuries. "(P3)

Participants revealed that they don't check health condition of the athletes due to the unavailability of specific medical team that has authority and capability to conduct medical check up. In this case, participant is a coach that also acted as medical officer.

"Yes, it is because in this women futsal team, there is no specific medical officer to give more thorough attention to the health condition of the athletes. "(P1)

"Because we are just coaches that also act as medical officer" (P1)

"That makes a health check up to the athletes can't be carried out because we are not medical officers." (P2)

"Actually, because there is no specific medical officer, coach finally also plays as medical team. I think this is difficult to be conducted since we are lack of human resource and there is no specific medical team. There is actually a doctor that should have been a doctor in this futsal team, but from the first match until now, he never comes to the exercise session or to the match due to his business and his other activities. "(P3)

\section{B. Early Assessment of Sport Injuries}

Before handling sport injuries, a medical officer should be able to locate where the injuries happened, tenderness, injury mechanism, and to evaluate the athletes' movement. Result from in depth interview showed that they have made early assessment of sport injuries although it hasn't followed the procedure of early assessment of sport injuries. In this case, the medical officers made assessment of sport injuries by using Talk, Observe, and Touch technique, but it is not followed by active and passive movement technique.

Early assessment of sport injuries on active and passive movement. The assessment of active and passive movement was conducted to evaluate movement that can be made actively or passively. Most of the participants said that they haven't applied active and passive movement technique as they feel that movement aspect isn't really necessary to be investigated. However, participants tend to assess sport injuries by only seeing, having conversation, and touching, as stated by the participants during the interview session.

"It doesn't need to be checked, a when a bump happened and the athlete feels the pain and his movement will be bothered. We could be sure that an injury incident happened"(P1)

"Sometimes yes, sometimes no. it depends on the situation of the match. When the athlete collides, we check the injury and ask her if they could move the injured part. When it still can be moved and the athlete can continue playing, it means that she can still play during the game." (P2) P2)

"Actually, it can be done. But, it is rarely done until now"(

"To check the movement, it is rarely done actually.. because by asking, observing, and touching, I think it's enough to check whether the athlete is injured. But maybe, the movement should also have been checked."(P3)

\section{Prevention of Sport Injuries}

Participants of the study have made actions to prevent the injuries take place by giving treatments in the form of regular exercise, skills training, food diet, and aid giving. However, the preventive action through environmental hasn't been conducted. The setting of environmental needs to be carried out to protect the athletes from getting injured due to the unsafe environmental. For instance, tools that aren't carefully stored could be a danger for athletes that can make them fall. All of the participants said that they tend to focus on the athletes condition rather than then environmental condition as preventive actions. Preventive actions through environmental aren't only carried out by the medical officer from the team but also by the committee of the match. They can set the managerial of the place tools. Some of responses dealing with prevention of the injuries through environmental from the participants are quoted as follows.

"We don't really focus on the environmental setting. "(P1)

“Environmental setting is not given specific attention”(P2)

"Yes, the environmental setting doesn't necessarily need to be conducted particularly.”(P3)

Participants also said that prevention through environmental can't be done since they focus on the athlete's condition, as ca be seen from the quotation below.

"Because we focus on the athlete condition. I admit that the condition of environmental also needs to be put attention but it depends to the individual coach, in which the need to 
aware of their tools position. The condition of the field also depends on the area condition.."(P1)

"Because we give our more attention to the athletes, in addition we feel that the environmental is clear enough." (P2)

"Because it also needs the cooperation from the athletes to be tidy and disciplined to create a safe and good environmental to play."(P3)

\section{Handling and Healing Sport Injuries}

1) Handling closed wounded of sport injuries

The data from interview showed that participants conducted various ways to handle and heal sport injuries, one of them is by applying Rest, Ice, Compress, Elevation (RICE) method. This method is started by resting the part that is injured, then followed by giving ice and let it compress the area for a while and make the position of the injured part higher than the heart position. The three respondents applied this method to handle close wounded, as stated below:

"For the first time, when the incident happened, we always do RICE"(P1)

"When the athlete get injured and she can't continue to play, we tend to do RICE treatment. That's the most standard treatment that is by giving ice and let it compress the wounded area and make its position elevated. "(P2)

"When a player is indicated to have close wounded injury, the first treatment that is given is RICE. Rest, ice, compress, and elevation. Rest means that the athlete is asked to rest, then the injured part is given ice and it can be compressed by strapping, meanwhile elevation is related to the way the athlete rest." (P3)

\section{2) Handling open wounded of sport injuries}

The participants carried out several ways to handle open wounded, for instance by controlling the bleeding, curing and cleaning the wounds, and closing the wound. Two respondents stated that they control the bleeding of the open wounds, as stated below:

"For open wounds, it usually happens on knees, when the it is still bleeding, we need to stop the bleeding." (P1)

"If there is an open wound, we should control the bleeding at first." (P3)

The following step after stopping the bleeding is cleaning the wound by giving antiseptic, as admitted below:

"When it is not bleeding, but it's only scuffed area, we usually clean it by water and then give it medicine"(P1)

"The wound is cleaned by using water flow" $(P 2)$

"After controlling the bleeding and it stops bleeding, the wound is sterilized by giving antiseptic"(P3)

"After that the wound is given medicine, like betadine"(P3)

All of the respondents stated that the next step after the wound is cleaned and sterilized by giving antiseptic is by closing the wound, as can be reflected through their statements:
"When the wound is only small scuffed area, it doesn't need to be closed, but if it is an open wound, it needs to be closed by gauze."(P1)

"When the player got injured and it is open wound, it needs to be closed when she wants to keep playing"(P2)

"After cleaning the wound and giving medicine, we need to close the wound so as to make the wounded clean to avoid infection to the wounded area" (P3)

\section{DISCUSSION}

\section{A. Medical Check Up in the Pre-competition Phase}

This theme describes the experience of medical officers in conducting health check up of the athletes before competition. The three members of women futsal medical team haven't conducted a thorough and comprehensive medical check up to their athletes. However, they still conduct component check up or by giving regular exercise. When the athletes can join the regular exercise well, it can be claimed that the athletes are in a good health condition. A medical check-up before competition can't be carried out because members of the medical officers are not from medical background, but coaches that also acted as medical officer. In relation to this condition, the current medical officers expect there will be a specific medical team that can handle health condition of the athletes after considering its importance. A medical check-up before the match is very important to ensure the athletes' health condition, ensure their fitness, detect bad situation to be fixed, and also to detect injuries (Tilarso, 2018). This is in line with Ackarmen at al (2009) who states that before an athlete participate in any sport, s/he needs to have medical check-up to ensure that $\mathrm{s} / \mathrm{he}$ is physically ready to play.

\section{B. Initial Assessment of Sport Injuries}

The experience of participant being medical officers in relation to initial assessment of sport injuries notes that this step is crucial to identify the injuries so that the injuries will get suitable treatment. In assessing sport injuries, women futsal medical team identified injuries mechanism, injuries location, injuries history, the tenderness and its movement. One of the ways in assessing sport injuries is through active and passive movement. This assessing method is applied to identify injuries area when making movements, an indicator to identify sport injuries. The participants of the study have made assessment of sport injuries, although it hasn't been done comprehensively. The medical team conducted assessing of the injuries by applying Talk, Observe, and Touch technique. They haven't applied another technique, active and passive movement technique to identify moving ability of the athletes that is actually can be done actively or passively. This happens because by applying talk, observe, and touch technique, the medical team believes that it is enough to identify the injuries. However, they also realize that assessing movement of the athletes is necessary to be carried out. This is supported by a statement that assessing movement is essential to identify potential risk factors by looking at risk of getting muskulosceletal injuries that is possible to happen (Schneiders, et.al,2011). This finding explains the importance of assessing 
injuries in more comprehensive ways, including by applying active and passive movement technique.

\section{Prevention of Sport Injuries through Environmental}

Preventing sport injuries can be done through several ways, including skills training, regular physical exercise, good diet, injuries handling, and also environmental setting. The participants of the study also have carried out those aforementioned ways except preventing injuries by environmental setting. This happens because the participants who are also coaches tend to give more attention to their athletes condition rather than to the environmental and they also think that the environmental has been safe enough for their athletes to play. Setting the environmental to be a safe are to play needs cooperation from various related parties, for example with the committee of the match. This way of preventive action needs more attention since this may also contribute to decrease potential risk of getting injured due to unsafe environmental. This is in accordance with Soemardiawan \& Bakar (2014) who state that preventive action through environmental setting needs to be done because some cases of injuries happened due to unsafe environmental. The environmental setting can be carried out by giving regulation to save tools and belongings in a designated place so that they won't harm anyone.

\section{Handling and Healing Sport Injuries}

Handling injuries is conducted based on the type of wounds caused by the injury incidents. In general, there are two types of wounds, close wounds and open wounds. The medical team as the ones who are considered responsible to handle the sport injuries, needs to be well-acknowledged about good and effective ways to handle and heal the wounds. The data revealed that to handle close wounded injuries, Rest, Ice,
Compress, Elevation (RICE) method is applied. This method is started by resting the part that is injured, then followed by giving ice and let it compress the area for a while and make the position of the injured part higher than the heart position. Meanwhile, open wounded injuries are handled by controlling the bleeding, cleaning the wounds by giving antiseptics, and ended by closing the wounds.

\section{CONCLUSION}

The health team's experience in sports injuries in female futsal athletes is sufficient, but aspects of the health examination, assessment and prevention of injuries have not been comprehensively carried out because the health team members are not from the health profession.

\section{REFFERENCES}

[1] E. Giza, C. Fuller, A. Junge and J. Dvorak, Mechanisms of foot and ankle injuries, 2003

[2] J. Dvorak and A. Junge, "Football injuries and physical symptoms a review of the literature," The American Journal of Sports Medicine, 2000

[3] G. Gabrilo, M. Ostojić, K. Izidrović, B. Novosel, and D. Sekulić, "A retrospective survey on injuries in Croatian football/soccer referees," BMC Musculoskeletal Disorders, 2013.

[4] M. Abate, C. Schiavone, and V. Salini, "High prevalence of patellar and Achilles tendinopathies in futsal athletes," Journal of Sports Science and Medicine, 2012

[5] P. Mufty, L. Bollars, K. Vanlommel, K. Van Crombrugge, J. Corten, and Bellemans, Injuries in male versus female soccer players : Epidemiology of a nationwide study S, 2015

[6] E. Ergen, F. Pigozzi, N. Bachl, and H.H. Dickhuth, "Sports medicine: a European perspective," Historical roots, definitions and scope, 2006.

[7] L.J. Moleong, Metodologi penelitian kualitatif. Bandung: PT Remaja Rosdakarya, 2014 